\title{
Improving the monitoring of chronic heart failure in Argentina: is the implantable pulmonary artery pressure with CardioMEMS Heart Failure System cost-effective?
}

Andrea Alcaraz* ${ }^{*}$, Carlos Rojas-Roque, Daniela Prina, Juan Martín González, Andrés Pichon-Riviere, Federico Augustovski and Alfredo Palacios

\begin{abstract}
Background: The CardioMEMS ${ }^{\circledR}$ sensor is a wireless pulmonary artery pressure device used for monitoring symptomatic heart failure (HF). The use of CardioMEMS was associated with a reduction of hospitalizations of HF patients, but the acquisition cost could be high in low-and-middle income countries. Evidence of cost-effectiveness is needed to help decision-makers to allocate resources according to "value for money". This study is aimed at estimating the cost-effectiveness of CardioMEMS used in HF patients from the third-party payer perspective -Social Security (SS) and Private Sector (PS)- in Argentina.

Methods: A Markov model was developed to estimate the cost-effectiveness of CardioMEMS versus usual medical care over a lifetime horizon. The model was applied to a hypothetical population of patients with HF functional class III with at least one hospitalization in the previous 12 months. The main outcome was the incremental costeffectiveness ratio (ICER). To populate the model we retrieved clinical, epidemiological and utility parameters from the literature, whilst direct medical costs were estimated through a micro-costing approach (exchange rate USD $1=$ ARS 76.95). Uncertainties in all parameters were assessed by deterministic, probabilistic and scenario sensitivity analysis.

Results: Compared with the usual medical care, CardioMEMS increased quality-adjusted life years (QALY) by 0.37 and increased costs per patient by ARS 1,081,703 for SS and ARS 919,051 for PS. The resultant ICER was ARS 2,937,756 per QALY and ARS 2,496,015 per QALY for SS and PS, respectively. ICER was most sensitive to the hazard ratio of HF hospital admission and the acquisition price of CardioMEMS. The probability that CardioMEMS is cost-effective at one (ARS 700,473), three (ARS 2,101,419,) and five (ARS 3,502,363) Gross Domestic Product per capita is 0.6, 17.9 and 64.1\% for SS and $5.4,33.3$ and $73.2 \%$ for PS.

Conclusions: CardioMEMS was more effective and more costly than usual care in class III HF patients. Since in Argentina there is no current explicit threshold, the final decision to determine its cost-effectiveness will depend on the willingness-to-pay for QALYs in each health subsector.
\end{abstract}

Keywords: Heart failure, Pulmonary artery pressure monitoring, Cost-effectiveness, Argentina

*Correspondence: aalcaraz@iecs.org.ar

Health Technology Assessment and Health Economics Department, Institute for Clinical Effectiveness and Health Policy (IECS), Doctor Emilio Ravignani 2024, Buenos Aires, Argentina

\section{Background}

Heart failure (HF) is a public health concern due to its high prevalence and lethality, resulting in reduced life expectancy [1] and an impaired quality of life [2].

c) The Author(s) 2021. This article is licensed under a Creative Commons Attribution 4.0 International License, which permits use, sharing, adaptation, distribution and reproduction in any medium or format, as long as you give appropriate credit to the original author(s) and the source, provide a link to the Creative Commons licence, and indicate if changes were made. The images or other third party material in this article are included in the article's Creative Commons licence, unless indicated otherwise in a credit line to the material. If material is not included in the article's Creative Commons licence and your intended use is not permitted by statutory regulation or exceeds the permitted use, you will need to obtain permission directly from the copyright holder. To view a copy of this licence, visit http://creativeco mmons.org/licenses/by/4.0/. The Creative Commons Public Domain Dedication waiver (http://creativecommons.org/publicdomain/ zero/1.0/) applies to the data made available in this article, unless otherwise stated in a credit line to the data. 
Although there is an increasing use of pharmacological [3-9] and intracardiac device [10-13] therapy options that showed improved morbidity and mortality, HF is still a major burden to patients, their caregivers and the national healthcare systems. Estimates from the USA suggest that the total cost of HF is US $\$ 31$ billion and could increase to US $\$ 70$ billion in 2030 [14].

Most of the costs are incurred from hospitalizations to treat clinical decompensations of patients with HF [15]. One of the most important causes of HF decompensation is the non-treatment adherence to medical indications, both regarding medication and non-pharmacologic therapies; early diagnosis in this scenario allows early treatment adjustment [16]. Implantable hemodynamic sensors find their support in the relationship between hemodynamic variables such as left ventricular or pulmonary artery pressure (PAP), with the subsequent appearance of symptoms, functional limitation and prognosis of the disease. Although the effectiveness of remote monitoring depend on the particular device and patients' characteristics $[17,18]$, remote monitoring of PAP in patients with HF can enable medical professionals to access to additional pathophysiological information and improve decision-making to prevent hospitalizations and slow the progression of symptomatic HF [19-23].

The CardioMEMS sensor is a novel wireless PAP measurement. According to the results of the pivotal randomized controlled trial (CHAMPION) [21], the device can be considered for monitoring symptomatic patients to reduce HF hospital admissions and the economic burden [24]. CardioMEMS have been approved to be used in the USA by the Food and Drug Administration (FDA) $[25,26]$, and the Heart Failure Association of the European Society of Cardiology (ESC) included the device in the ESC guidelines for the diagnosis and treatment of acute and chronic HF [24]. Previous economic evaluations showed that CardioMEMS is cost-effective in the USA [27-29] and is likely to be cost-effective in the United Kingdom [30].

In Argentina, the use of CardioMEMS was approved in 2015 [31], but there is no evidence to assess the costeffectiveness of devices for monitoring PAP. Evidence of the cost-effectiveness of HF management strategies is needed to help decision-makers to allocate scarce resources to address the mortality and morbidity burden, as well as to reduce the growing costs for patients and the healthcare system. Argentina is an interesting case of study due to the great fragmentation and segmentation of the health system [32]. Three large subsectors can be identified: the public, social security and private sector. The public sector covers $100 \%$ of the population, but approximately $36.5 \%$ (15.7 million of people) have exclusive public coverage $[33,34]$. Social security is the most important sector within the health system, giving coverage to $60 \%$ ( 26 million) of the population. This sector is organized in three large groups: (i) 269 Obras Sociales Nacionales (OSNs) covering 14 million, generally composed of workers within the same labor activity and their core family members, (ii) 24 Obras Sociales Provinciales (OSPs) covering 7 million, generally composed of public employers, and (iii) the nationwide social health insurance fund for retired workers (PAMI, acronym in Spanish), covering 4.8 million elderly people and people with disabilities [33, 34]. Lastly, the private sector covers approximately 6 million, where 2 million are enrolled on an individual basis through direct and voluntary payment, while the remaining 4 million comes from the OSNs by contracting private supplementary plans $[33,34]$. In addition, the high prevalence of HF (1-1.5\%), especially in people older than 65 years in which prevalence is up to 8 times higher [16], adds relevance to the study.

This study is aimed at estimating cost-effectiveness measured through incremental costs per QALY of CardioMEMS compared to the usual medical care, from the third-party payer perspective in patients with HF functional class III in Argentina.

\section{Methods \\ Decision model}

We developed a state transition (i.e., Markov) model in Microsoft Excel ${ }^{\circledR}$ (Microsoft Corp. Redmond, WA) to determine the cost-effectiveness of the use of CardioMEMS HF system compared to the usual medical care over a lifetime horizon, from the third-party payer perspective, in particular, for Social Security (SS) and Private Sector (PS) in Argentina.

The Markov model was applied to a hypothetical population of 1000 patients with characteristics similar to the patients enrolled in the CHAMPION trial [21, 35, 36]. This was the latest available evidence of efficacy and safety of CardioMEMS while this study was ongoing. Thus, in the model we include patients with diagnosis of HF class functional (CF) III (according to the classification of the New York Heart Association (NYHA) [37]) regardless of the systolic ejection fraction, with at least one hospitalization for decompensation of HF during the previous 12 months. It was compared to 1000 hypothetical patients that received usual medical care consisting of optimized drug treatment and followed up according to the criteria of the attending physician.

The outcome of our model is the incremental costeffectiveness ratio (ICER), which compares the difference in costs divided by the differences in Quality Adjusted Life Years (QALY) of CardioMEMS versus usual medical care. Nowadays, in Argentina, there is no 
explicit threshold to define an intervention as cost-effective, it is necessary to define a decision rule, defined as the willingness-to-pay for the health outcome that will be later used as a threshold. We adopted a willingnessto-pay threshold between 1 (ARS 700,473) and 3 (ARS 3,502,363) Gross Domestic Product (GDP) per capita based on decision rules estimated for low-and middle income countries [38-40], and previous economic evaluations published in Argentina [41-43] and based on the recommendation of the World Health Organization of 3 times the GDP [44]. Lastly, we explored a willingness-topay threshold of 5 GDP per capita since the technology is recommended for end-of-life care, for a disease associated with short life expectancy that would be extended thanks to the technology. The latter approach to consider a higher willingness-to-pay has been considered by the National Institute for Health and Care Excellence (NICE) in the United Kingdom upon establishing the criteria for the appraisal of end-of-life treatments [45]. We applied an annual discount rate of $5 \%$ for costs and QALY, as recommended by the economic evaluation guidelines for countries member of MERCOSUR [46], and we followed the CHEERS guidelines to report our findings [47].

\section{Model structure}

To define the model structure, we reviewed previously published specialized literature and economic models [27-30, 48]. Subsequently, we repeatedly resorted to the opinion of cardiology experts in order to validate the structure of the model in the local context. Our Markov model considered four health states: "Heart failure functional class III (stable)", "HF hospital admission", "Post HF hospital admission" and "Death" (Fig. 1). There are two cohorts in the model, those who receive the CardioMEMS device (treatment cohort) and those who receive the usual medical care (control cohort). For both cohorts, HF patients transitioned through different states in monthly cycles, accruing costs and QALYs. The length of the cycles in the model was defined as monthly because,

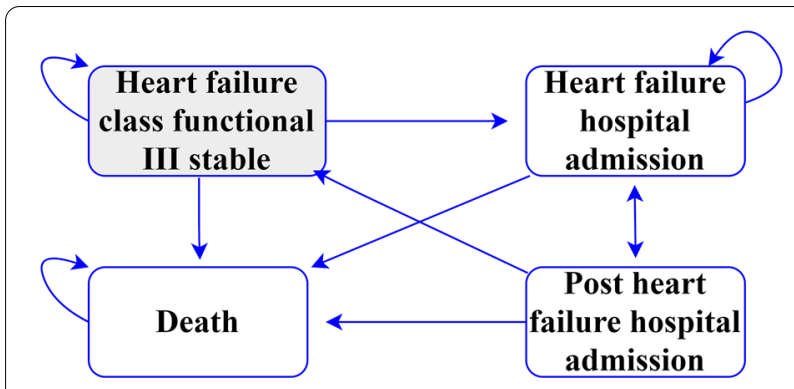

Fig. 1 Analytic structure of the model. Gray square represents the initial state in the model during this time frame, the patients face high mortality and morbidity rates. The monthly cycles used are aligned with the previous economic evaluations performed [2730, 48].

Before entering the model, the individuals in the treatment cohort accrue an initial incremental cost related to the implantation of the device and its complications (including acute mortality). We included the eight CardioMEMS complications reported in the Manufacturer and User Facility Device Experience (MAUDE) database, which collect mandatory and voluntary reports of devicerelated malfunctions, injuries or deaths received by the FDA [49]. In each cohort, patients enter to the model and may remain outpatient/stable, or they may require HF hospital admission or die. After a cycle, patients who entered the HF hospital admission state and are still alive enter the post HF hospital admission cycle and then return to an outpatient/stable cycle or require another hospital admission. Patients hospitalized and in the post HF hospital admission cycle have higher odds to die and accrue lower QALYs in comparison to patients who remain outpatient/stable.

Other assumptions were that the model did not consider non-HF hospital admission, because we assume they were equal in both cohorts. In addition, no adverse events associated with the pharmacological treatment received were considered, since the medication scheme was assumed to be the same in both cohorts.

\section{Epidemiological parameters}

Every epidemiological parameter was retrieved by performing a literature search of the evidence regarding the patients and the intervention of the study. We select the evidence that suits the best and represents the local context. Epidemiological parameters are reported in Table 1.

The mortality for the patients in the treatment cohort at month 12 of follow-up was 16\% (95\% CI: 14-18\%), based on the largest study published with the device: a multi-center, prospective, open-label, observational, single-arm trial, that assessed the efficacy and safety of CardioMEMS with 1200 patients [35]. The mortality for the control cohort was based on the life tables by age of the Argentine population and was calibrated through an intermediate correction factor that represents the excess of risk associated with HF in Argentina. The resulting correction factor, equal to 7.7 , means that patients with HF CF III have an increased relative risk of death of 7.7 in comparison to those patients without HF. This correction factor for mortality was calculated by calibrating the baseline mortality rate of our model in the control cohort with the mortality rate observed in the control arm of the CHAMPION trial (23\% at 18 months) [21]. 
Table 1 Summary of input parameters

\begin{tabular}{|c|c|c|c|c|}
\hline Parameter & Base case & Variability range $^{a}$ & $\begin{array}{l}\text { Probability } \\
\text { distribution }\end{array}$ & Source \\
\hline \multicolumn{5}{|l|}{ Clinical, efficacy and epidemiological parameters } \\
\hline Baseline mean age of $\mathrm{HF}$ patients entering model & 66 & 61 to 69 & Normal & $\begin{array}{l}\text { Weighted mean based on heart failure } \\
\text { registries in Argentina }\end{array}$ \\
\hline Baseline risk of HF hospital admission & 1.13 & 0.68 to 1.55 & Beta & Author estimations based on $21,35,36$ \\
\hline HR of HF hospital admission, CardioMEMS cohort & 0.48 & 0.38 to 0.67 & Log normal & Meta-analysis based on 21, 35, 36 \\
\hline Baseline risk of mortality at 12 month of follow-up & 0.16 & 0.14 to 0.18 & Beta & 35 \\
\hline HR of risk of mortality due to HF hospital admission & 3.32 & 1.00 to 5.00 & Log normal & 51 \\
\hline Complications, treatment cohort (1-7 month) & 0.03 & 0.02 to 0.04 & Beta & 49 \\
\hline $\begin{array}{l}\text { Mortality due to device implantation procedure } \\
(1-7 \text { month) }\end{array}$ & 0.004 & 0.003 to 0.005 & Beta & 49 \\
\hline \multicolumn{5}{|l|}{ Utility parameters } \\
\hline Baseline utility & 0.711 & 0.027 & Beta & 21 \\
\hline $\begin{array}{l}\text { Monthly change of utility for month } 1 \text { to } 6 \text {, treatment } \\
\text { cohort }\end{array}$ & 0.001 & 0.001 & Beta & 21 \\
\hline $\begin{array}{l}\text { Monthly change of utility for month } 7 \text { to } 60 \text {, treatment } \\
\text { cohort }\end{array}$ & 0.003 & 0.003 & Beta & 21 \\
\hline $\begin{array}{l}\text { Monthly change of utility for month } 1 \text { to } 6 \text {, control } \\
\text { cohort }\end{array}$ & -0.005 & 0.004 & Beta & 21 \\
\hline $\begin{array}{l}\text { Monthly change of utility for month } 7 \text { to } 60 \text {, control } \\
\text { cohort }\end{array}$ & -0.003 & 0.003 & Beta & 21 \\
\hline Disutility of HF hospital admission & 0.045 & 0.012 & Beta & 28 \\
\hline \multicolumn{5}{|l|}{ Costs parameters, in ARS } \\
\hline Cost of CardioMEMS device & $1,392,182$ & $1,044,137$ to $1,740,228$ & Normal & Abbott \\
\hline Implant procedure & $\begin{array}{l}\text { SS: } 100,878 \\
\text { PS: } 137,090\end{array}$ & $\begin{array}{l}\text { SS: } 75,659 \text { to } 126,098 \\
\text { PS: } 102,818 \text { to } 171,363\end{array}$ & Normal & 56 \\
\hline Weighted average cost of device complications ${ }^{b}$ & $\begin{array}{l}\text { SS: } 144,482 \\
\text { PS: } 193,445\end{array}$ & $\begin{array}{l}\text { SS: } 108,362 \text { to } 180,603 \\
\text { PS: } 145,084 \text { to } 227,954\end{array}$ & Normal & 56 \\
\hline Monthly device monitoring cost & $\begin{array}{l}\text { SS: } 973 \\
\text { PS: } 1,502\end{array}$ & $\begin{array}{l}\text { SS: } 730 \text { to } 1,217 \\
\text { PS: } 1,126 \text { to } 1,877\end{array}$ & Normal & 56 \\
\hline Standard HF care cost & $\begin{array}{l}\text { SS: } 4,512 \\
\text { PS: } 5,440\end{array}$ & $\begin{array}{l}\text { SS: } 3,384 \text { to } 5,641 \\
\text { PS: } 4,080 \text { to } 6,800\end{array}$ & Normal & 56 \\
\hline Hospital admission for HF cost & $\begin{array}{l}\text { SS: } 362,788 \\
\text { PS: } 534,983\end{array}$ & $\begin{array}{l}\text { SS: } 272,091 \text { to } 453,485 \\
\text { PS: } 401,237 \text { to } 655,753\end{array}$ & Normal & $56-58$ \\
\hline
\end{tabular}

PSA Probabilistic sensibility analysis, HF heart failure, HR hazard ratio, LMCCF last mothly change carried forward, SS Social Security, PS Private Sector ${ }^{a}$ Varibility range for the clinical, efficacy and epidemiological parameters are reported as $95 \%$ confidence interval; variability range for the utility parameters are presented as standard deviation; variability range for the cost parameters are reported as minimum and maximum values

${ }^{b}$ The costs of the eight CardioMEMS complications were estimated as a weighted average according to its frequency

Exchange rate US $\$ 1=$ ARS 76.95

The baseline mean age of patients entering the model was based on the weighted sample size mean age of patients with chronic HF reported in the Heart Failure Registries of Argentina [50]. To obtain the mean hazard ratio of heart failure hospital admission for patients in the treatment cohort, we performed a meta-analysis, including the CHAMPION trial [21] and two multi-center, prospective, open-label, observational single-arm trials that evaluated the efficacy and safety of CardioMEMS in patients with HF class III, in the USA and Europe [35, 36]. This meta-analysis was also used to obtain the mean of HF hospital admission events per patient-year. The decision of using all the internationally available evidence was made since in Argentina the Heart Failure Registry does not differentiate the rate of hospital admissions or the hospital admission events per person-year according to the classification of NYHA.

\section{Treatment effect of CardioMEMS}

Due to the uncertainty of CardioMEMS regarding the direct effect on mortality, and since mortality in patients with HF increases during hospitalization and the subsequent month [51,52], we indirectly modelled the effect on mortality through the decrease in the probability of 
HF hospital admission. We incorporated an increased risk of mortality [53] for HF hospital admission state and post HF hospital admission state (Table 1), a similar approach adopted by others [48]. CardioMEMS effect on HF hospital admission was modeled using the hazard ratio obtained in our meta-analysis, which included 3 studies [21, 35, 36]. For the base case analysis, these benefits were assumed to last five years, and disappeared after this period. This conservative decision was made due to the uncertainty regarding the long-term effects of the device, similar to a previous economic evaluation [30].

\section{Health-related quality of life}

Data regarding baseline health-related quality of life (HRQoL) at 6 and 12 months was based on the EuroQol Quality of Life Five Dimensions instrument (EQ-5D) [54] and collected in the CHAMPION trial [21]. At baseline, the HRQoL is 0.711 for both cohorts, and at 6 and 12 months the HRQoL is 0.719 and 0.739 for the treatment cohort respectively, while for the control cohort the HRQoL at 6 and 12 months is 0.681 and 0.66 , respectively. Based on this data, we calculated the monthly change of HRQoL and distributed it evenly over the intervals for months 1-6 and for months 7-60 for both cohorts. In the model, we assumed that the effect of CardioMEMS on HRQoL at month 12 is carried forward to month 60 , and after that we assumed that the differences in utilities disappeared between both cohorts. This assumption is similar to the approach taken in previous economic evaluations [28]. The impact of HF hospital admission in utilities (or disutilities) was based on Schmier and colleagues [28]. We compared the Minnesota Quality of Life Questionnaire scores reported by CHAMPION trial with those reported in a local study [55], and the values were similar, suggesting EQ-5D scores could be applicable to Argentina.

\section{Direct medical costs}

We applied a micro-costing approach to estimate the direct medical costs for a third-party payer perspective (SS and PS). Identification and quantification of healthcare resources were made by a local literature review, validated by consultation to local experts, whilst unit cost estimations were made using the Healthcare Cost Database of the Institute for Clinical Effectiveness and Health Policy (IECS) [56]. This database contains unit cost information based on the tariffs of medical resources and practices for SS and PS subsectors. Direct medical costs were updated to September 2020 and were expressed in Argentinian pesos (ARS) (exchange rate USD $1=$ ARS 76.95).
The CardioMEMS device acquisition price was provided by the manufacturer and was ARS 1,398,182. The cost of CardioMEMS implantation was assumed to be equivalent to the cost of the right heart catheterization and angiography, a similar assumption made in another economic evaluation [27]. The costs of the eight CardioMEMS complications [49] were estimated as a weighted average according to its frequency. Death has no cost in the model. We consulted clinical experts to monetize the monthly cost of device monitoring.

Pharmacological treatment in the outpatient/stable cycle is based on the local clinical practice guidelines [16] and standard HF healthcare costs were estimated according to the local clinical practice guidelines for the treatment of HF [16]. The identification and quantification of the healthcare resources during the HF hospital admission in Argentina was based on two local studies [57, 58]. After this, we estimated the unit costs by using IECS Healthcare Cost Database [56].

\section{Sensitivity analysis}

Uncertainty was assessed with one-way deterministic sensitivity analysis (Table 1). Due to the heterogeneity in the HF population, we assessed the baseline mortality risk, the baseline risk of hospital admission, the average age of HF population, and we also included the acquisition cost of the device. A probabilistic sensitivity analysis was performed using 1000 Monte Carlo simulations, in which, with each simulation, we sampled from the distributions of each input parameter. The range of values incorporated in these analyses is shown in Table 1.

\section{Scenario analysis}

We assessed the uncertainty of CardioMEMS effect on patients through two analyses of alternative scenarios. In the first scenario, the treatment effect of CardioMEMS was extended to a lifetime horizon. In the second scenario, the effect of CardioMEMS lasts 18 months (equal to the follow-up time in the CHAMPION trial), and from this point, the effect progressively declines until the fifth year, when it finally disappears. Lastly, we also report the undiscounted base case results.

\section{Results \\ Base case results}

The parameters used in the model are reported in Table 1. In the base case analysis (lifetime horizon) with a discount rate of $5 \%$, the CardioMEMS HF system increased QALYs in the treatment cohort in comparison to the control cohort by 0.37 . CardioMEMS also increased costs compared to usual medical care by ARS 1,081,703 for SS and ARS 919,051 for PS (Table 2). The 
Table 2 Base case results

\begin{tabular}{|c|c|c|c|c|c|c|c|c|}
\hline \multirow[t]{2}{*}{ Strategy } & \multicolumn{2}{|c|}{$\begin{array}{l}\text { Per patient cumulative costs } \\
\text { (ARS) }\end{array}$} & \multicolumn{2}{|c|}{ Incremental costs (ARS) } & \multirow[t]{2}{*}{$\begin{array}{l}\text { Per patient } \\
\text { cumulative } \\
\text { QALY }\end{array}$} & \multirow[t]{2}{*}{$\begin{array}{l}\text { Incremental } \\
\text { QALY }\end{array}$} & \multicolumn{2}{|c|}{$\begin{array}{l}\text { Incremental cost- } \\
\text { effectiveness ratio (ARS per } \\
\text { QALY) }\end{array}$} \\
\hline & Social security & Private sector & Social security & Private sector & & & Social security & Private sector \\
\hline \multicolumn{9}{|c|}{ Base case results with $5 \%$ discount rate } \\
\hline $\begin{array}{l}\text { Usual medical } \\
\text { manage- } \\
\text { ment }\end{array}$ & $1,440,033$ & $2,080,035$ & & & 1.98 & & & \\
\hline $\begin{array}{c}\text { CardioMEMS } \\
\text { HF System }\end{array}$ & $2,521,736$ & $2,999,087$ & $1,081,703$ & 919,051 & 2.35 & 0.37 & $2,937,756$ & $2,496,015$ \\
\hline \multicolumn{9}{|c|}{ Base case results without discount rate } \\
\hline $\begin{array}{l}\text { Usual medical } \\
\text { manage- } \\
\text { ment }\end{array}$ & $1,672,268$ & $2,415,684$ & & & 2.29 & & & \\
\hline $\begin{array}{c}\text { CardioMEMS } \\
\text { HF System }\end{array}$ & $2,726,678$ & $3,293,612$ & $1,054,410$ & 877,928 & 2.72 & 0.43 & $2,449,631$ & $2,039,625$ \\
\hline
\end{tabular}

$H F$ heart failure, $Q A L Y$ quality-adjusted life years

resultant ICER was ARS 2,937,756 per QALY and ARS 2,496,015 per QALY for SS and PS, respectively.

On the other hand, in the undiscounted base case analysis, CardioMEMS in comparison to usual medical care increased costs by ARS 1,054,410 and ARS 877,928 for SS and PS, respectively. QALY increased in the CardioMEMS cohort in comparison to the control cohort by 0.43 . The resulting ICER was ARS 2,449,631 and ARS 2,039,625 per QALY for SS and PS, respectively.

\section{Sensitivity analysis}

Figure 2 shows the one-way sensitivity analyses performed for both the SS and PS perspective. The ICER was most sensitive to the HR of HF hospital admission obtained in our meta-analysis, the acquisition cost of CardioMEMS and the mortality due to HF hospital admission, among other parameters. Reducing the HR of HF hospital admission to 0.38 [the base HR reported in Angermann et al. [36]] resulted in an ICER of ARS 2,225,077 and ARS 1,728,223 per QALY for SS and PS, respectively. On the other hand, increasing the HR to 0.67 (the HR reported in the CHAMPION trial [21]) increases the ICER to ARS 4,685,811 and ARS 4,382,352 per QALY for SS and PS, respectively. The ICER was also sensitive to the acquisition cost of the device. When we reduced the acquisition cost of CardioMEMS by 25\%, ICER resulted in ARS 1,924,020 per QALY for SS and ARS 1,457,693 for PS. A discount of $10 \%$ in the acquisition cost of CardioMEMS yields an ICER below 3 GDP per capita.

Another parameter that influenced the ICER result was HR of risk of mortality due to HF hospital admission (varied between 1 and 5). The resulting ICER varied from
ARS 2,683,044 to ARS 4,235,255 per QALY for SS and varied from ARS 2,379,068 to ARS 3,193,044 per QALY for PS. Lastly, when we varied the utility of CardioMEMS by its standard deviation, the ICER varied from ARS 2,503,120 to ARS 3,555,040 per QALY for SS and varied from ARS 2,126,734 to ARS 3,020,485 for PS. ICER was fairly less sensitive to the variabilities in the rest of the parameters.

We also assessed the uncertainty of the CardioMEMS effect on patients by performing two scenario analyses. Under the first scenario, with a lifelong lasting CardioMEMS effect, the resulting ICER was ARS 1,804,312 per QALY for SS and was ARS 1,407,515 per QALY for PS. Under the second scenario, with a CardioMEMS effect of 18 months and henceforth progressively declining to completely disappear on year five, the resulting ICER was ARS 3,966,795 per QALY for SS and was ARS 3,484,989 per QALY for PS.

\section{Probabilistic analysis}

Figure 3 shows the results of the probabilistic sensitivity analysis. For SS, all the points in the scatter plot fall in the right upper quadrant, confirming the high certainty that CardioMEMS is both more effective and more expensive than the usual medical care. These findings are quite similar for the PS sector. For both sectors, at one GDP per capita as a cost-effectiveness threshold almost the totality of the points are above the threshold. On the other hand, at five GDP per capita as a cost-effectiveness threshold, the majority of the points in both sectors fall below the curve.

Due to the potential heterogeneity in willingness-topay among different third-party payers from the same 


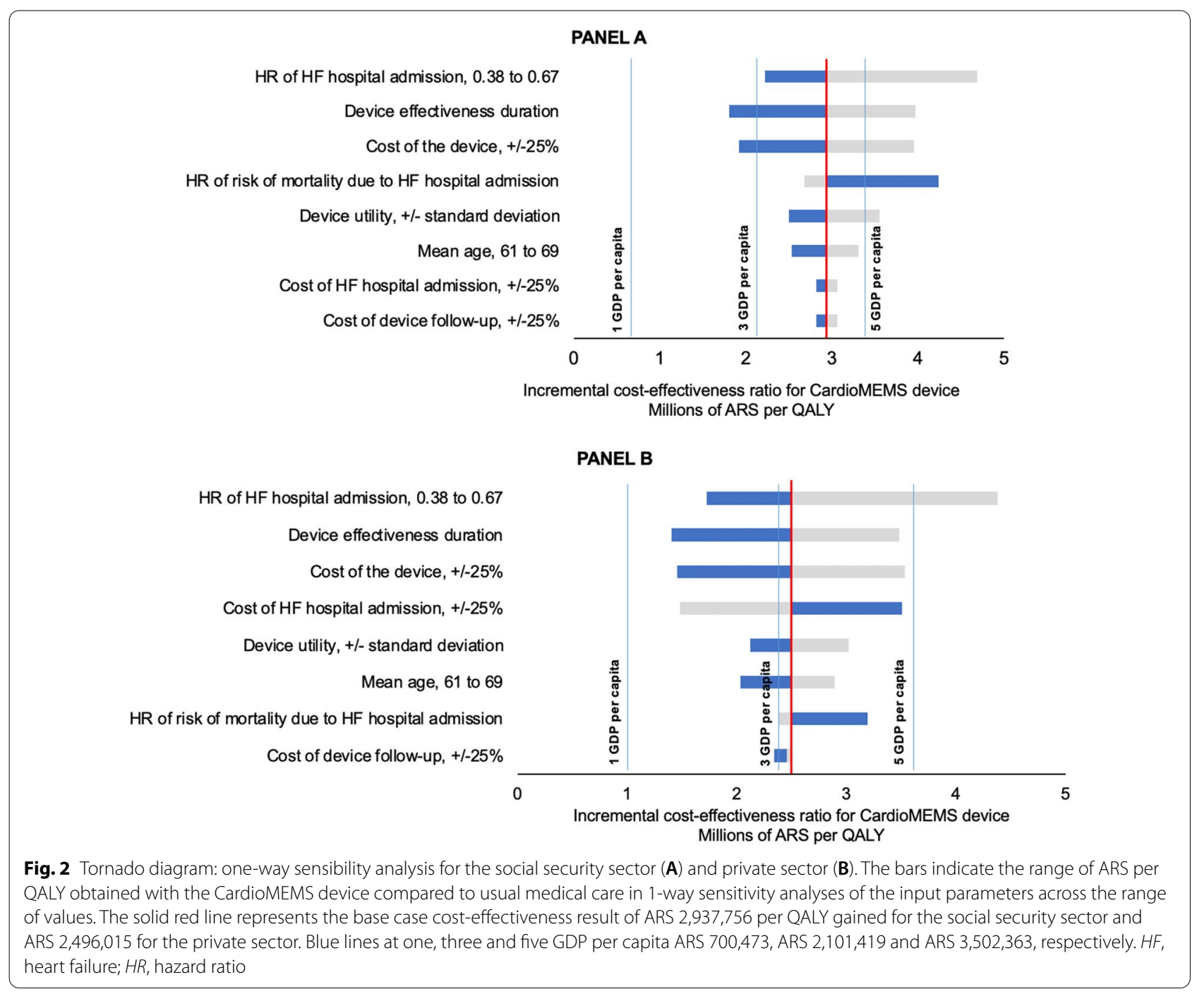

sectors in Argentina, we assessed several thresholds of willingness to pay. For the SS sector, the probability that CardioMEMS be cost-effective at one (ARS 700,473), three (ARS 2,101,419,) and five (ARS 3,502,363) GDP per capita is $0.6,17.9$ and $64.1 \%$. For the PS sector, the probabilities are 5.4, 33.3 and $73.2 \%$, respectively (Fig. 4).

\section{Discussion}

In contexts where resources for healthcare are scarce, health technologies assessments and economic evaluations are useful tools to evaluate the efficacy, safety, efficiency, and affordability of new healthcare technologies. From the efficacy and safety evidence of CardioMEMS HF system, this study assessed the costeffectiveness of CardioMEMS use in the Argentinian context. The analysis showed that base case ICER was between three to five GDP per capita per QALY gained. Although Argentina does not have an explicit cost-effectiveness threshold, this result could be above the efficiency threshold suggested by the literature [46, 47]. However, considering that the benefited population comprehends patients with advanced-stage HF and poor prognosis, the decision rule to determine cost-effectiveness of the device will depend on the willingness to pay for QALYs gained from each specific third-party payer in Argentina.

It is important to mention that in Argentina, as in other Latin American countries, health technology coverage decisions are not necessarily guided by cost-effectiveness criteria. For example, Pichon-Riviere and colleagues estimated the ICER for trastuzumab, a breast cancer drug available in several Latin American countries, and showed that for Argentina trastuzumab only could be cost-effective at a threshold of 8.47 GDP per capita [59].

Evidence of cost-effectiveness analysis suggests that CardioMEMS could be cost-effective in the USA and 


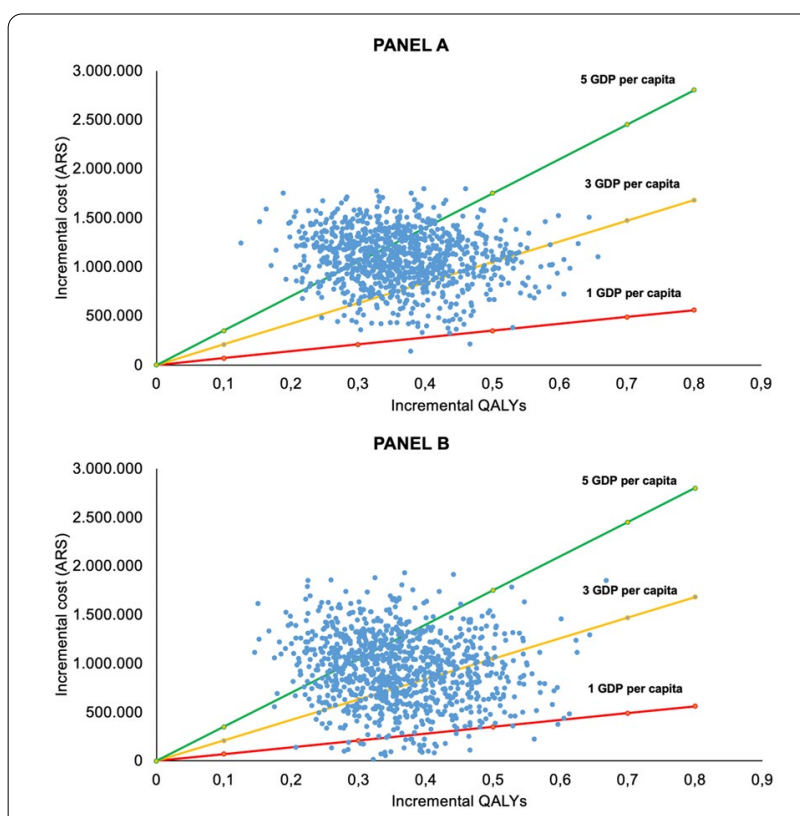

Fig. 3 Cost-effectiveness scatter plot for social security sector (A) and private sector (B), for different willingness-to-pay thresholds. One GDP per capita (ARS 700,473), three GDP per capita (ARS 2,101,419), and five GDP per capita (ARS 3,502,363). Each point in the scatter plot represents one simulation in the model with different input values sampled from the input distribution

UK settings, even though ICER varies widely due to the

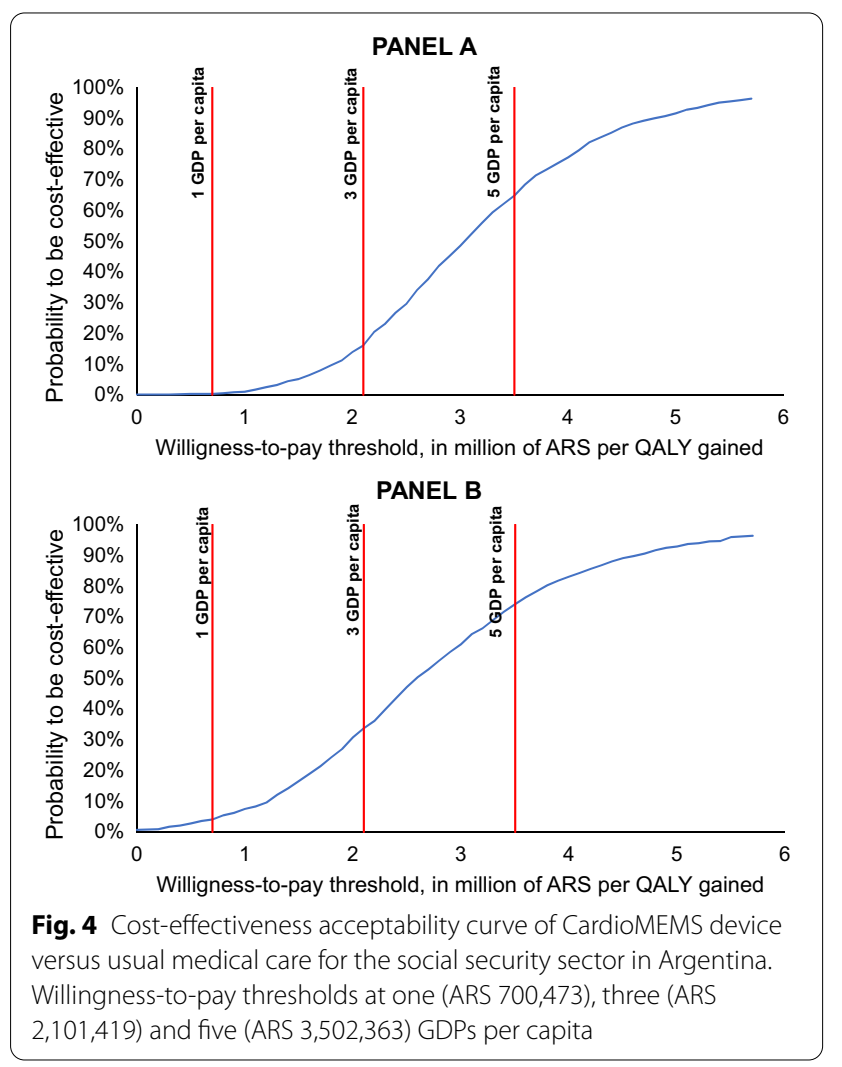

different time horizons adopted, the assumptions made in the effects of CardioMEMS on mortality, among other methodological aspects [27-30, 48]. The studies that incorporated a lifelong time horizon (as ours) showed a higher ICER than studies with a shorter analytic horizon, mainly due to the fact that the benefit of CardioMems declined through time. In our estimations, survival years, QALYs and HF hospital admissions averted were consistent with the estimations made by the studies that use lifetime horizons $[27,48]$.

In our model, among all parameters, ICER estimates were most sensitive to the HR of HF hospital admission. In the base case, to synthesize all the available evidence regarding the effectiveness of CardioMEMS on the hospital admission, we performed a meta-analysis using the pivotal trial [21] and two real-world evidence studies [35, 36]. In the one-way sensitive analysis we assessed the variability of this parameter by using the HR reported in Angermann and colleagues [36] and the HR reported in the CHAMPION trial [21], as they represent the extreme values in the available literature. In addition, we assessed all the treatment effects of CardioMEMS by performing two analyses of scenarios. In the best scenario where the treatment effect of CardioMEMS was lifelong, ICER fell below the 3 GDP per capita willingness-to-pay, but in the worst scenario where the treatment effect declined from month 18 and equal for both cohorts in month 60, ICER exceeded the 5 GDP per capita willingness-to-pay. We consider that our model incorporates a credible scenario for the base case, given that it is not possible to know whether the benefit of avoiding hospitalizations would continue as the patients get worse given that it is a progressive disease [60-62].

The results of the CHAMPION trial regarding the treatment effect of CardioMEMS on mortality were inconclusive [21], and studies of non-invasive remote monitoring systems have been neutral regarding the potential reduction in mortality $[63,64]$. Due to this uncertainty, our approach in the modelling was to capture this treatment effect indirectly from the increased risk of mortality during HF hospital admission and the following month. The expected benefit on QALYS could be higher (and the ICER lower) if the reduction in mortality risk is confirmed. This approach is more conservative than the one used in other economic evaluations [28-30], but is similar to the approach adopted in an economic evaluation performed in the USA [48]. The lack of proven effectiveness in mortality still has to be weighed against the benefits in quality of life and cost from the decrease in hospitalizations by decision-makers.

Our findings could have implications on CardioMEMS pricing policies. As the largest costs of the model are driven by the acquisition cost of CardioMEMS, we 
varied this parameter by $\pm 25 \%$. In the lowest price, ICER improves and falls below the 3 GDP per capita willingness-to-pay threshold on social security and a discount of $10 \%$ turns the ICER to 3 GDP in the private sector. This information together with budget impact analysis, is helpful to design pricing policies in the different health sectors in Argentina.

This study has some limitations to note. First, all the effectiveness and safety of CardioMEMS comes from a CHAMPION trial [21] and two real world studies [35, 36] that assessed effectiveness and safety at one year post implantation of CardioMEMS, thus the long-term efficacy is still unclear. To reduce the uncertainty, we performed a meta-analysis to summarize the best evidence available at the moment. In the near future, this meta-analysis should be updated as more post-surveillance evaluations become available. Second, the thirdparty payer perspective of this study prevented us from evaluating all the possible benefits and costs at a societal level. For example, reductions in the rate of HF hospital admissions could reduce indirect cost for patients (labor productivity loss costs, out-of-pocket expenditures) and favors medical attention to other HF and nonHF patients by reducing waiting time queue. Third, our model does not include some aspects of indirect saving that can improve the ICER, but there is a lack of information. For example, the time spent monitoring CardioMEMS, in spite of not influencing ICER results, is an important aspect to consider. CardioMEMS HF system seems plausible to require less time to monitor the device in comparison to other less advanced technologies such as telephone calls, anamnesis on body weight, diuretic rhythm and symptoms of dyspnea and fatigue. Fourth, we used a linear trajectory of utilities or disutilities; however, the relationship between patient-reported utilities and HF hospital admission may not be linear, since patients with multiple HF hospital admissions during an interval of time can report higher disutilities. Unfortunately, there is no data available to describe the utilities of HF patients regarding hospital admissions, but in our sensitivity analysis we widely assessed this parameter and did not show greater impact on ICER. Given the substantial societal and economic toll of HF, it is worthy to consider the previous aspects as soon as they become available. Incorporating these types of devices into the coverage package should take into account other strategies to improve patient adherence to treatment at the same time [65].

Despite these limitations, this study gives a clear snapshot about the cost-effectiveness of CardioMEMS in Argentina, underpin the finding with a model adapted to the local setting and using a nationally representative costs database to perform a micro-costing approach to estimate costs of health events. Furthermore, the sensibility analysis was useful to examine the multiple variability of ICER, thereby findings herein presented can promote the use of cost-effectiveness evidence in HF management strategy adoption at a national level. Future studies that refine estimates of the long-term effects of the device on mortality could reduce uncertainty and improve conclusions regarding its clinical and economic impact, contributing to informed healthcare decision-making.

\section{Conclusion}

CardioMEMS was more effective and more costly than usual care in class III HF patients in Argentina, being the ICER between three and five GDP per capita per QALY gained. The decision rule to determine the cost-effectiveness of the device will depend on the specific willingness to pay for QALY gained from each healthcare subsector.

\section{Acknowledgements \\ None.}

\section{Authors' contributions}

AA coordinated the project, advised on all aspects and co-wrote the final draft. AP, FA and APR advised on methods and all statistical aspects. JMG extracted and cleaned all the clinical, effectiveness, epidemiological and utility data and advised on all clinical aspects. DP constructed and implemented the cost-effectiveness model and performed time to event analysis. CRR extracted and estimated all the costs data and wrote the final draft. All authors contributed to the interpretation of the results and contributed to edit the final draft. All authors read and approved the final manuscript.

\section{Funding}

This work was supported by Abbott Argentina. The sponsor of the study had no role in the study design, data collection, data analysis, data interpretation or writing the manuscript. The corresponding author had full access to all the data.

\section{Availability of data and materials}

The datasets analyzed in this study are available from the corresponding author on reasonable request.

\section{Declarations}

Ethics approval and consent to participate Not applicable.

\section{Consent for publication}

Not applicable.

\section{Competing interests}

This study was made possible by the support of Abbott Argentina through a research grant. The contents are the responsibility of the authors.

Received: 8 April 2021 Accepted: 30 June 2021

Published online: 09 July 2021

\section{References}

1. Jhund PS, Macintyre K, Simpson CR, Lewsey JD, Stewart S, Redpath A, et al. Long-term trends in first hospitalization for heart failure and subsequent survival between 1986 and 2003: a population study of 5.1 million people. Circulation. 2009;119(4):515-23. https://doi.org/10.1161/CIRCU LATIONAHA.108.812172. 
2. Jeon Y-H, Kraus SG, Jowsey T, Glasgow NJ. The experience of living with chronic heart failure: a narrative review of qualitative studies. BMC Health Serv Res. 2010;10:77. https://doi.org/10.1186/1472-6963-10-77.

3. SOLVD Investigators, Yusuf S, Pitt B, Davis CE, Hood WB, Cohn JN. Effect of enalapril on survival in patients with reduced left ventricular ejection fractions and congestive heart failure. N Engl J Med. 1991;325(5):293-302. https://doi.org/10.1056/NEJM199108013250501.

4. Effect of metoprolol CR/XL in chronic heart failure. Metoprolol CR/XL randomised intervention trial in congestive heart failure (MERIT-HF). Lancet. 1999;353(9169):2001-7.

5. Pitt B, Zannad F, Remme WJ, Cody R, Castaigne A, Perez A, et al. The effect of spironolactone on morbidity and mortality in patients with severe heart failure. Randomized Aldactone Evaluation Study Investigators. N Engl J Med. 1999;341(10):709-17. https://doi.org/10.1056/NEJM199909 023411001

6. Packer M, Poole-Wilson PA, Armstrong PW, Cleland JG, Horowitz JD, Massie BM, et al. Comparative effects of low and high doses of the angiotensin-converting enzyme inhibitor, lisinopril, on morbidity and mortality in chronic heart failure ATLAS Study Group. Circulation. 1999;100(23):2312-8. https://doi.org/10.1161/01.cir.100.23.2312

7. Cohn JN, Tognoni G, Valsartan Heart Failure Trial Investigators. A randomized trial of the angiotensin-receptor blocker valsartan in chronic heart failure. N Engl J Med. 2001;345(23):1667-75. https://doi.org/10. 1056/NEJMoa010713.

8. Pfeffer MA, Swedberg K, Granger CB, Held P, McMurray JJV, Michelson $\mathrm{EL}$, et al. Effects of candesartan on mortality and morbidity in patients with chronic heart failure: the CHARM-Overall programme. Lancet. 2003;362(9386):759-66. https://doi.org/10.1016/s0140-6736(03)14282-1.

9. Maggioni AP, Anand I, Gottlieb SO, Latini R, Tognoni G, Cohn JN, et al. Effects of valsartan on morbidity and mortality in patients with heart failure not receiving angiotensin-converting enzyme inhibitors. J Am Coll Cardiol. 2002;40(8):1414-21. https://doi.org/10.1016/s0735-1097(02) 02304-5.

10. Moss AJ, Zareba W, Hall WJ, Klein H, Wilber DJ, Cannom DS, et al. Prophylactic implantation of a defibrillator in patients with myocardial infarction and reduced ejection fraction. N Engl J Med. 2002;346(12):877-83. https://doi.org/10.1056/NEJMoa013474.

11. Cleland JGF, Daubert J-C, Erdmann E, Freemantle N, Gras D, Kappenberger $L$, et al. The effect of cardiac resynchronization on morbidity and mortality in heart failure. N Engl J Med. 2005;352(15):1539-49. https://doi. org/10.1056/NEJMoa050496.

12. Bristow MR, Saxon LA, Boehmer J, Krueger S, Kass DA, De Marco T, et al. Cardiac-resynchronization therapy with or without an implantable defibrillator in advanced chronic heart failure. N Engl J Med. 2004;350(21):2140-50. https://doi.org/10.1056/NEJMoa032423.

13. Bardy GH, Lee KL, Mark DB, Poole JE, Packer DL, Boineau R, et al. Amiodarone or an implantable cardioverter-defibrillator for congestive heart failure. N Engl J Med. 2005;352(3):225-37. https://doi.org/10.1056/NEJMo a043399.

14. Heidenreich PA, Albert NM, Allen LA, Bluemke DA, Butler J, Fonarow $\mathrm{GC}$, et al. Forecasting the impact of heart failure in the United States: a policy statement from the American Heart Association. Circ Heart Fail. 2013;6(3):606-19. https://doi.org/10.1161/HHF.0b013e318291329a.

15. Dunlay SM, Shah ND, Shi Q, Morlan B, VanHouten H, Long KH, et al. Lifetime costs of medical care after heart failure diagnosis. Circ Cardiovasc Qual Outcomes. 2011;4(1):68-75. https://doi.org/10.1161/CIRCOUTCOM ES.110.957225.

16. Sociedad Argentina de Cardiología. Consenso de Insuficiencia Cardiaca Crónica [Internet]. 2016;84:54. https://www.sac.org.ar/wp-content/uploa ds/2016/10/consenso-de-insuficiencia-cardiaca-cronica-2016-1.pdf. Accessed 15 Jan 2021

17. Hawkins NM, Virani SA, Sperrin M, Buchan IE, McMurray JJV, Krahn AD. Predicting heart failure decompensation using cardiac implantable electronic devices: a review of practices and challenges. Eur J Heart Fail. 2016;18(8):977-86. https://doi.org/10.1002/ejhf.458.

18. Kitsiou S, Paré G, Jaana M. Effects of home telemonitoring interventions on patients with chronic heart failure: an overview of systematic reviews. J Med Internet Res. 2015. https://doi.org/10.2196/jmir.4174.

19. Adamson PB, Magalski A, Braunschweig F, Böhm M, Reynolds D, Steinhaus $D$, et al. Ongoing right ventricular hemodynamics in heart failure clinical value of measurements derived from an implantable monitoring system. J Am Coll Cardiol. 2003;41(4):565-71. https://doi.org/10.1016/ s0735-1097(02)02896-6.

20. Bourge RC, Abraham WT, Adamson PB, Aaron MF, Aranda JM Jr, Magalski A, et al. Randomized controlled trial of an implantable continuous hemodynamic monitor in patients with advanced heart failure: the COMPASSHF study. J Am Coll Cardiol. 2008;51(11):1073-9. https://doi.org/10.1016/j. jacc.2007.10.061.

21. Abraham WT, Adamson PB, Bourge RC, Aaron MF, Costanzo MR, Stevenson $\mathrm{LW}$, et al. Wireless pulmonary artery haemodynamic monitoring in chronic heart failure: a randomised controlled trial. Lancet. 2011;377(9766):658-66. https://doi.org/10.1016/S0140-6736(11)60101-3.

22. Abraham WT, Adamson PB, Hasan A, Bourge RC, Pamboukian SV, Aaron MF, et al. Safety and accuracy of a wireless pulmonary artery pressure monitoring system in patients with heart failure. Am Heart J. 2011;161(3):558-66. https://doi.org/10.1016/j.ahj.2010.10.041.

23. Abraham WT, Stevenson LW, Bourge RC, Lindenfeld JA, Bauman $J G$, Adamson PB, et al. Sustained efficacy of pulmonary artery pressure to guide adjustment of chronic heart failure therapy: complete follow-up results from the CHAMPION randomised trial. Lancet. 2016;387(10017):453-61. https://doi.org/10.1016/S0140-6736(15) 00723-0.

24. Ponikowski P, Voors AA, Anker SD, Bueno H, Cleland JGF, Coats AJS, et al. 2016 ESC Guidelines for the diagnosis and treatment of acute and chronic heart failure: the Task Force for the diagnosis and treatment of acute and chronic heart failure of the European Society of Cardiology (ESC). Developed with the spec. Eur J Heart Fail. 2016;18(8):891-975. https://doi.org/10.1002/ejhf.592.

25. FDA. The CardioMEMS ChampionTM HF Monitoring System for Patients with NYHA Class III Heart Failure: Draft Briefing Document for the Circulatory Systems Device Panel Advisory Committee Food and Drug Administration [Internet]. 2011. https://www.accessdata.fda.gov/cdrh docs/pdf10/p100045c.pdf. Accessed 15 Jan 2021.

26. FDA. Brief Summary of the Circulatory System Devices Panel Meeting. Food and Drug Administration. 2011 [cited 2020 Jan]. www.fda.gov/ downloads/AdvisoryCommittees/CommitteesMeetingMaterials/Medic alDevices/MedicalDevicesAdvisoryCommittee/CirculatorySystemDev icesPanel/UCM283470.pdf. Accessed 15 Jan 2021.

27. Sandhu AT, Goldhaber-Fiebert JD, Owens DK, Turakhia MP, Kaiser DW, Heidenreich PA. Cost-effectiveness of implantable pulmonary artery pressure monitoring in chronic heart failure. JACC Heart Fail. 2016;4(5):368-75. https://doi.org/10.1016/j.jchf.2015.12.015.

28. Schmier JK, Ong KL, Fonarow GC. Cost-effectiveness of remote cardiac monitoring with the CardioMEMS Heart Failure System. Clin Cardiol. 2017:40(7):430-6. https://doi.org/10.1002/clc.22696.

29. Martinson M, Bharmi R, Dalal N, Abraham WT, Adamson PB. Pulmonary artery pressure-guided heart failure management: US cost-effectiveness analyses using the results of the CHAMPION clinical trial. Eur J Heart Fail. 2017;19(5):652-60. https://doi.org/10.1002/ejhf.642.

30. Cowie MR, Simon M, Klein L, Thokala P. The cost-effectiveness of realtime pulmonary artery pressure monitoring in heart failure patients: a European perspective. Eur J Heart Fail. 2017;19(5):661-9. https://doi.org/ 10.1002/ejhf.747.

31. ANMAT. Disposición No.8421 Administración Nacional de Medicamentos, Alimentos y Tecnología Médica. 2015. http://www.anmat.gov.ar/boletin_ anmat/octubre_2015/Dispo_8421-15.pdf. Accessed 15 Jan 2021.

32. Palacios A, Espinola N, Rojas-Roque C. Need and inequality in the use of health care services in a fragmented and decentralized health system: evidence for Argentina. Int J Equity Health. 2020;19(1):67. https://doi.org/ 10.1186/s12939-020-01168-6.

33. Rubinstein A, Zerbino MC, Cejas C, López A. Making universal health care effective in Argentina: a blueprint for reform. Health Syst Reform. 2018;4(3):203-13. https://doi.org/10.1080/23288604.2018.1477537.

34. Cetrángolo O, Goldschmit A. Organization and financing of health provision by social security in Argentina IIEP. Facultad de Ciencias Económicas. Universidad de Buenos Aires; 2018. http://bibliotecadigital.econ.uba.ar/ download/docin/docin_iiep_025.pdf. Accessed 15 Jan 2020.

35. Shavelle DM, Desai AS, Abraham WT, Bourge RC, Raval N, Rathman LD, et al. Lower rates of heart failure and all-cause hospitalizations during pulmonary artery pressure-guided therapy for ambulatory heart failure: one-year outcomes from the CardioMEMS Post-Approval Study. Circ Heart Fail. 2020. https://doi.org/10.1161/CIRCHEARTFAILURE.119.006863. 
36. Angermann CE, Assmus B, Anker SD, Asselbergs FW, Brachmann J, Brett $M-E$, et al. Pulmonary artery pressure-guided therapy in ambulatory patients with symptomatic heart failure: the CardioMEMS European Monitoring Study for Heart Failure (MEMS-HF). Eur J Heart Fail. 2020 https://doi.org/10.1002/ejhf.1943.

37. Levin R, Dolgin M, Fox C, Gorlin R. The criteria committee of the new york heart association: nomenclature and criteria for diagnosis of diseases of the heart and great vessels. LWW Handbooks. 1994;9:344.

38. Eichler H-G, Kong SX, Gerth WC, Mavros P, Jönsson B. Use of costeffectiveness analysis in health-care resource allocation decision-making: how are cost-effectiveness thresholds expected to emerge? Value Health. 2004;7(5):518-28. https://doi.org/10.1111/j.1524-4733.2004.75003.x.

39. Shillcutt SD, Walker DG, Goodman CA, Mills AJ. Cost effectiveness in low- and middle-income countries: a review of the debates surrounding decision rules. Pharmacoeconomics. 2009;27(11):903-17. https://doi.org/ 10.2165/10899580-000000000-00000.

40. Woods B, Revill P, Sculpher M, Claxton K. Country-level cost-effectiveness thresholds: initial estimates and the need for further research. Value Health. 2016;19(8):929-35. https://doi.org/10.1016/j.jval.2016.02.017.

41. Augustovski F, Chaparro M, Palacios A, Shi L, Beratarrechea A, Irazola V, et al. Cost-effectiveness of a comprehensive approach for hypertension control in low-income settings in Argentina: trial-based analysis of the hypertension control program in Argentina. Value Health. 2018;21(12):1357-64. https://doi.org/10.1016/j.jval.2018.06.003.

42. Garay OU, Palacios A, Pichon-Riviere A, Augustovski F, Martí SG, Hernández-Vásquez A, et al. The Cost-effectiveness of continuous versus intermittent renal replacement therapies in acute kidney injury: perspective of the social services for the elderly in Argentina. Value Health Reg Issues. 2019;20:142-8. https://doi.org/10.1016/j.vhri.2019.03.008.

43. Espinola N, Maceira D, Palacios A. Cost-effectiveness of colorectal cancer screening tests in Argentina. Acta Gastroenterol Latinoam. 2016;46(1):8-17.

44. World Health Organization. Commission on macroeconomics and health Sachs J, World Health Organization. Macroeconomics and Health: Investing in Health for Economic Development World Health Organization. Geneva: World Health Organization; 2001. p. 200.

45. Collins M, Latimer N. NICE's end of life criteria: who gains, who loses? BMJ. 2013;346(7905):22-3.

46. Directrices metodológicas para estudios de evaluación económica de tecnologías sanitarias MERCOSUR SGT No.11 P. RES. No. 06/09. 2009. http://bancos.salud.gob.ar/sites/default/files/2018-10/0000000626cnt-4guia-evaluacion-econ.pdf. Accessed 22 Mar 2021

47. Augustovski F, Garay OU, Pichon-Riviere A, Rubinstein A, Caporale JE. Economic evaluation guidelines in Latin America: a current snapshot. Expert Rev Pharmacoecon Outcomes Res. 2010;10(5):525-37. https://doi.org/10. 1586/erp.10.56.

48. ICER. CardioMEMSTM HF System (St. Jude Medical, Inc.) and Sacubitril/ Valsartan (EntrestoTM, Novartis AG) for management of congestive heart failure: effectiveness, value, and value-based price benchmarks institute for clinical and economic review; 2015. https://icer.org/wp-content/ uploads/2020/10/CHF_Final_Report_120115.pdf. Accessed 27 Mar 2020.

49. Vaduganathan M, DeFilippis EM, Fonarow GC, Butler J, Mehra MR. Postmarketing adverse events related to the CardioMEMS HF system. JAMA Cardiol. 2017;2(11):1277-9. https://doi.org/10.1001/jamacardio.2017. 3791.

50. Roque-Perna E, Coronel ML, Címbaro-Canella JP, Exchazarreta D. Revisión de insuficiencia cardíaca en Argentina Avances y retrocesos luego de dos décadas de registros y más de 19000 pacientes incluidos. Insuficiencia Cardíaca. 2015;10(1):2-10.

51. Solomon SD, Dobson J, Pocock S, Skali H, McMurray JJV, Granger CB, et al. Influence of nonfatal hospitalization for heart failure on subsequent mortality in patients with chronic heart failure. Circulation. 2007;116(13):1482-7. https://doi.org/10.1161/CIRCULATIONAHA.107. 696906.

52. Bello NA, Claggett B, Desai AS, McMurray JJV, Granger CB, Yusuf S, et al. Influence of previous heart failure hospitalization on cardiovascular events in patients with reduced and preserved ejection fraction. Circ Heart Fail. 2014;7(4):590-5. https://doi.org/10.1161/CIRCHEARTFAILURE. 113.001281.

53. O'Connor CM, Abraham WT, Albert NM, Clare R, Gattis Stough W, Gheorghiade $\mathrm{M}$, et al. Predictors of mortality after discharge in patients hospitalized with heart failure: an analysis from the Organized Program to Initiate Lifesaving Treatment in Hospitalized Patients with Heart Failure (OPTIMIZE-HF). Am Heart J. 2008;156(4):662-73. https://doi.org/10.1016/j. ahj.2008.04.030.

54. Phillip BA, Bharmi R, Bauman JG, Dalal N, Martinson M, Abraham W. Cost effectiveness assessment of pulmonary artery pressure monitoring for heart failure management. Heart Rhythm. 2015;12(5):S82.

55. Zambrano C, Badra R, Cerezo G, Ferrante D, Soifer S, Varini S, et al. Seguimiento al año luego de finalizada la intervención telefónica en pacientes con insuficiencia cardíaca crónica: estudio DIAL. Rev Argent Cardiol. 2005;73(1):7-14.

56. Institute for Clinical Effectiveness and Health Policy (IECS). Unit Cost Base in Health in Argentina IECS. 2018. https://www.iecs.org.ar/. Accessed 23 Mar 2021.

57. Waisman G, Garfi L, Tortella J, Izbizky G, Marcheti M, Aguero C. Costos médicos directos de las internaciones por insuficiencia cardíaca en el Plan de Salud del Hospital Italiano de Buenos Aires. Rev Fac Cienc Médicas. 2018;75(1):3-11.

58. Augustovski F, Caporale J, Fosco M, Alcaraz A, Diez M, Thierer J, et al. Uso de recursos y costos de hospitalizaciones por insufi ciencia cardiaca: un estudio retrospectivo multicéntrico en Argentina. Value Health Reg Issues. 2017:14:73-80.

59. Pichon-Riviere A, Garay OU, Augustovski F, Vallejos C, Huayanay L, del Bueno MPN, et al. Implications of global pricing policies on access to innovative drugs: the case of trastuzumab in Seven Latin American Countries. Int J Technol Assess Health Care. 2015;31(1-2):2-11. https://doi.org/ 10.1017/S0266462315000094.

60. Drummond M, Brown R, Fendrick AM, Fullerton P, Neumann P, Taylor R, et al. Use of pharmacoeconomics information-report of the ISPOR Task Force on use of pharmacoeconomic/health economic information in health-care decision making. Value Health. 2003;6(4):407-16. https://doi. org/10.1046/j.1524-4733.2003.64245.x.

61. Caro JJ, Briggs AH, Siebert U, Kuntz KM, ISPOR-SMDM Modeling Good Research Practices Task Force. Modeling good research practices-overview: a report of the ISPOR-SMDM Modeling Good Research Practices Task Force-1. Med Decis Making. 2012;32(5):667-77. https://doi.org/10. 1177/0272989X12454577.

62. Eddy DM, Hollingworth W, Caro JJ, Tsevat J, McDonald KM, Wong JB, et al. Model transparency and validation: a report of the ISPOR-SMDM Modeling Good Research Practices Task Force-7. Med Decis Making 2012;32(5):733-43. https://doi.org/10.1177/0272989X12454579.

63. Ong MK, Romano PS, Edgington S, Aronow HU, Auerbach AD, Black $J T$, et al. Effectiveness of remote patient monitoring after discharge of hospitalized patients with heart failure: the better effectiveness after transition - heart failure (BEAT-HF) randomized clinical trial. JAMA Intern Med. 2016;176(3):310-8. https://doi.org/10.1001/jamainternmed.2015. 7712.

64. Koehler F, Winkler S, Schieber M, Sechtem U, Stangl K, Böhm M, et al. Impact of remote telemedical management on mortality and hospitalizations in ambulatory patients with chronic heart failure: the telemedical interventional monitoring in heart failure study. Circulation. 2011;123(17):1873-80. https://doi.org/10.1161/CIRCULATIONAHA.111. 018473.

65. Unverzagt S, Meyer G, Mittmann S, Samos F-A, Unverzagt M, Prondzinsky R. Improving treatment adherence in heart failure. Dtsch Arztebl Int. 2016;113(25):423-30. https://doi.org/10.3238/arztebl.2016.0423.

\section{Publisher's Note}

Springer Nature remains neutral with regard to jurisdictional claims in published maps and institutional affiliations. 